\title{
Mitochondrial optic neuropathy: In vivo model of neurodegeneration and neuroprotective strategies
}

\author{
This article was published in the following Dove Press journal: \\ Eye and Brain \\ 10 March 2010 \\ Number of times this article has been viewed
}

\author{
Julio C Rojas \\ Francisco Gonzalez-Lima \\ Departments of Psychology, \\ Pharmacology and Toxicology, \\ University of Texas at Austin, \\ Austin, TX, USA
}

Correspondence: Francisco Gonzalez-Lima University of Texas at Austin, I University Station A8000, Austin, TX 787 I2, USA Tel + I 512 47| 5895

Fax +I 512 47| 4728

Email gonzalez-lima@mail.utexas.edu

\begin{abstract}
This review summarizes the characteristics of a rodent toxicologic model of optic neuropathy induced by the mitochondrial complex I inhibitor rotenone. This model has been developed to fulfill the demand for a drug-screening tool providing a sound mechanistic context to address the role of mitochondrial dysfunction in the pathogenesis of neurodegenerative disorders. It features biochemical, structural, and functional retinal deficits that resemble those of patients with Leber's hereditary optic neuropathy, a mitochondrial disease characterized by selective degeneration of retinal ganglion cells, and for which an environmental component is believed to play a major triggering role. The available data support the efficiency, sensitivity, and versatility of the model for providing insights into the mechanisms of neurodegeneration, including mitochondrial dysfunction, oxidative stress and excitotoxicity. Screening work with this model has provided proof-of-principle that interventions targeting the electron transport chain, such as USP methylene blue and near-infrared light therapy, are effective at preventing neurodegeneration induced by mitochondrial dysfunction in vivo. Prospective developments of this model include the use of neuronal reporter genes for in vivo non-invasive assessment of retinal degeneration at different time points, and its combination with genetic approaches to elucidate the synergism of environmental and genetic factors in neurodegeneration.
\end{abstract}

Keywords: animal model, neuroprotection, mitochondrial dysfunction, visual function, oxidative stress, cytochrome oxidase

\section{Introduction}

The retina has historically constituted an extremely useful window to the brain. Studies of the retina have helped in developing primordial knowledge about the properties of the brain, and its structure and function. The great value of the retina for the study of the brain is best exemplified by the extensive use of retinal examination by clinicians to assess the status of the intracranial compartment. ${ }^{1}$ Also, studies of the retina were instrumental in the establishment of the neuron doctrine by Ramon y Cajal, ${ }^{2}$ and visual deficit studies allowed Hubel and Wiesel to gain insights into the functional organization and plasticity of the brain. ${ }^{3}$

More recently, Howell ${ }^{4}$ has advocated that Leber's hereditary optic neuropathy (LHON), a classical retinal neurodegenerative condition described by Thomas Leber in 1871, could be a model for understanding the role of mitochondrial dysfunction in neurodegeneration. LHON has a distinct anatomic phenotype and clinical progression that differs from the slow course typically characteristic of other neurodegenerative diseases. In this regard, LHON is unique and has no parallel in the clinical spectrum of neurodegenerative entities. Nevertheless, understanding the mechanisms 
of neurodegeneration featured by a condition with a clear mitochondrial pathogenesis such as LHON, could provide insights into the role of mitochondrial dysfunction as part of the pathogenesis of major neurodegenerative disorders, a role that is strongly suggested by recent literature. Howell's idea stems from the hypothesis that major late-onset neurodegenerative disorders may share a common mitochondrial pathogenesis with LHON. This common mitochondrial component would then provide "a point through which (the neurodegenerative disorders) can be attacked experimentally, theoretically, and-most importantly-therapeutically". ${ }^{4}$ Indeed, there is a tremendous need to develop effective therapeutic interventions against neurodegenerative disorders. These conditions impair the quality of life of patients and their families in a devastating way, and represent a significant burden to public health systems worldwide. ${ }^{5,6}$ Treatment options currently available for patients with neurodegenerative disorders provide temporary symptomatic relief only and do not modify the progression of neurodegeneration. ${ }^{7-10}$ To this day, interventions that effectively slow or prevent the natural history of neurodegeneration remain a crucial unmet need.

Mitochondria are central organelles in neuronal physiology. They coherently integrate cell respiration, energy metabolism, and calcium ion balance to support cell survival. Mitochondrial dysfunction is a hallmark of mitochondriopathies, a group of rare disorders characterized by impairment of the respiratory chain and abnormalities in tissues with high metabolic demands, such as muscle and brain. Recently, common sporadic neurodegenerative conditions such as Alzheimer's disease (AD), Parkinson's disease (PD) and Huntington's disease (HD) have also been associated with major mitochondrial functional abnormalities. ${ }^{11-13}$ Neurodegenerative disorders are heterogeneous in their manifestations and most likely in their etiology, but all are characterized by progressive neuronal loss. Since mitochondrial bioenergetics plays a central role in neuronal survival, it can be hypothesized that the putative heterogeneous etiologic factors of neurodegeneration may find in mitochondria points of vulnerability for neuronal integrity, thus triggering neuronal death pathways mediated by mitochondrial dysfunction.

There is now a vast body of evidence showing that mitochondrial failure is linked to known major pathogenic aspects of neuronal dysfunction associated with neurodegeneration, including excitotoxicity, ${ }^{14}$ abnormal protein aggregation, ${ }^{15}$ neuroinflammation, ${ }^{16}$ and oxidative stress. ${ }^{17}$ Previously, this evidence appeared somewhat disconnected, but it can be now unified into a sound theory that highlights the possible pathogenic contribution of mitochondrial dysfunction (Figure 1). However, the importance of mitochondria in neurodegeneration has not been thoroughly taken into account in preclinical and clinical protocols aimed at drug development. Based on the current evidence, targeted manipulations of mitochondrial function seem to be the next logical step in attempts to design effective therapeutic interventions against neurodegeneration.

\section{Leber's hereditary optic neuropathy}

LHON has a number of characteristics that make it attractive as a model of neurodegeneration. First, LHON resembles more common neurodegenerative conditions (ie, AD, PD, HD) in that it manifests with early degeneration of particular neuronal networks, which highlights their intrinsic vulnerability. LHON is characterized by an acute-to-subacute bilateral loss of central vision caused by selective degeneration of the retinal ganglion cell layer and the optic nerve. ${ }^{18}$ Second, LHON was the first neurodegenerative condition for which a mitochondrial pattern of inheritance was described. ${ }^{19}$ In LHON, the risk of retinal ganglion cell degeneration and vision loss follows a strict maternal inheritance pattern, regardless of whether or not the mother is visually affected. ${ }^{20}$ About $96 \%$ of families with individuals affected with LHON carry one of three point mutations in mitochondrial DNA (mDNA). These mutations occur in nucleotides 3460, 11778, or 14484, and result in amino acid substitutions in the ND1, ND4 and ND6 genes, respectively. ${ }^{21}$ Such genes are three of seven mitochondrial genes that encode subunits of the membrane-embedded sector of NADH dehydrogenase (complex I) of the mitochondrial electron transport chain (ETC). Finally, LHON is not only a neurodegenerative disorder with a predictable inheritance pattern, but is also one for which a straightforward etiology involving mitochondrial dysfunction has been widely acknowledged.

There is a substantial body of evidence showing that mitochondrial mutations in LHON lead to optic nerve degeneration by impairing normal mitochondrial function, although the exact mechanism is still controversial. The primary hypothesis of the pathogenesis of LHON holds that because LHON mutations are found in mitochondrial complex I genes, they induce neurodegeneration by impairing complex I function and energy production..$^{22,23}$ Complex I is the initial step in a cascade of inner mitochondrial membrane reactions that regulate the controlled release of energy from high-energy electrons. These reactions allow the transformation of electron energy into an energy currency that is usable 

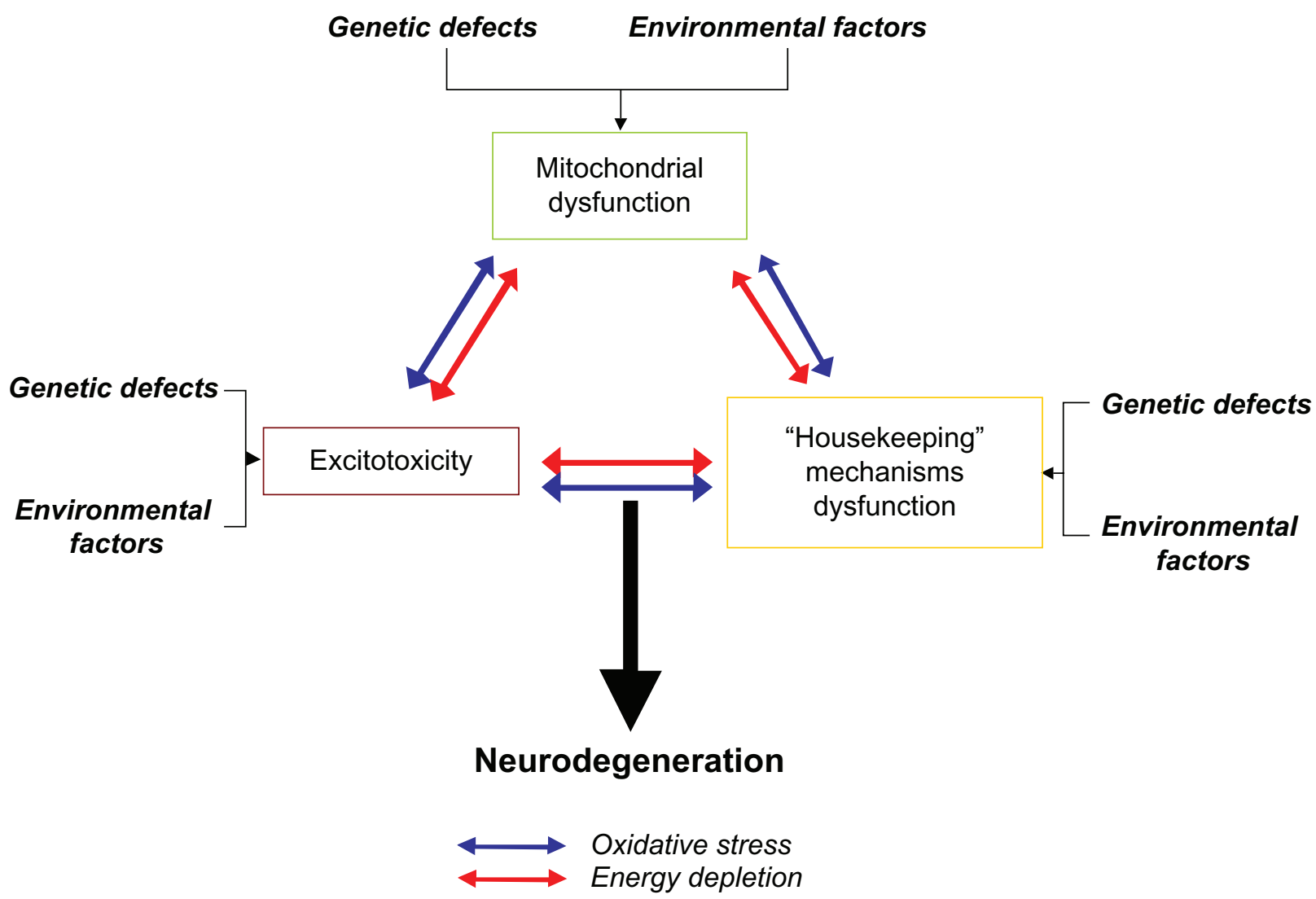

Figure I Role of mitochondrial dysfunction in the pathogenesis of neurodegeneration. Neurodegeneration is likely to have a heterogeneous set of genetic and environmental causes that vary between individual cases. Current evidence suggests that genetic and environmental factors induce neurodegeneration through three major neurodegenerative events, comprising mitochondrial dysfunction, excitotoxicity, and dysfunction of housekeeping mechanisms (ie, proteasome, antioxidant). Two mediators of neurodegeneration, which constitute immediate consequences of mitochondrial failure, ie, oxidative stress and energy depletion, are responsible for promoting excitotoxic damage and dysfunction of housekeeping systems. A reciprocal pathophysiological interaction between mitochondrial dysfunction, excitotoxicity, and housekeeping dysfunction is proposed, in which activation of any of these events not only triggers a vicious cycle that promotes its self-propagation, but leads to the onset and exacerbation of the others. The amplified effects of this process, in turn, lead to the activation of cell death pathways, when it is severe enough or when it is unopposed by the appropriate homeostatic responses.

by neurons, ie, adenosine triphosphate (ATP). It has been demonstrated that, although highly variable, the pathogenic mutations induce complex I inhibition. For example, the 3460 mutation induces a $60 \%-80 \%$ decrease in complex I activity and a $30 \%$ decrease in cellular respiratory rate, whereas the 11778 mutation induces decreases in complex I activity that range from $0 \%$ to $30 \%{ }^{24}$ There is also some evidence suggesting that LHON mutations induce a major impairment in ATP synthesis. ${ }^{4,21,25}$ Furthermore, the three pathogenic mutations have been shown to impair the NADH/NAD balance, ${ }^{4}$ which is not only regulated by energy storage, but also by levels of oxidative stress. Complex I is known to be a major mitochondrial source of reactive oxygen species. In fact, complex I dysfunction increases high-energy electron leak from the N2 iron-sulfur cluster of complex I. ${ }^{26}$ Leaking electrons can thus react with oxygen to form superoxide, a major reactive oxygen species involved in oxidative stress. Transfection of mutant ND4 subunits into rat retinal ganglion cell-like cells via adeno-associated virus vectors has been shown to elevate reactive oxygen species, disrupt mitochondrial structure, and induce apoptosis. ${ }^{27}$ These data suggest that the expression of mutated complex I subunits induces improper redox and energy balances that are likely to trigger retinal neurodegeneration.

\section{Environmental etiologies}

One of the most challenging issues concerning the pathogenesis of LHON is that, despite it being a model genetic neurodegenerative condition, only $50 \%$ of males and $10 \%$ of females who carry the pathogenic mutations develop the disease. ${ }^{4}$ The incomplete penetrance in LHON shows that the mutations are necessary but not sufficient for its clinical expression. In turn, it also strongly suggests that the clinical expression is modulated by epigenetic or environmental factors interacting with the phenotype induced by the mutations. There is compelling evidence showing that environmental factors might act synergistically with the pathogenic LHON mutations to induce mitochondrial 
dysfunction and trigger the expression of the disease. First, the disease is not congenital, but mainly affects individuals in early adulthood. Also, several cases of monozygous twins discordant for LHON have been described. ${ }^{28-32}$ In one case, occupational exposure to smoke was believed to be the trigger of vision loss in the affected twin. Alcohol and tobacco use have been associated with the course of LHON in a number of anecdotal reports. ${ }^{29,33,34}$ Recently, an epidemiologic analysis of 196 affected and 206 unaffected carriers from 125 LHON families identified a strong dose-response association between visual loss and the intensity of smoking, independent of genotype, gender, and alcohol intake..$^{35}$ The effect led to a clinical penetrance of $93 \%$ in men who smoked compared with $66 \%$ in non-smoking males. In support of this finding, the mean platelet complex I activity has been shown to be reduced by $24 \%$ in healthy tobacco smokers, compared with healthy non-smokers. ${ }^{36}$ Kirkman et a ${ }^{35}$ also reported a trend towards increased visual loss with heavy alcohol intake, and 33\% of patients reported occupational or accidental toxin exposure (ie, exhaust fumes, dry cleaning solvents, asbestos, lead, scrap metals, or fiberglass) in the immediate period preceding visual loss.

In fact, a number of toxic optic neuropathies including tobacco-alcohol amblyopia, Cuban optic neuropathy, and chloramphenicol optic neuropathy, share the clinical features of LHON, and are considered part of a common spectrum of disorders. ${ }^{37,38}$ Methanol poisoning which causes acute retinotoxicity and major photoreceptor degeneration in humans has also been proposed to be mediated by mitochondrial dysfunction, and has been successfully modeled in rodents..$^{39,40}$ In addition, the fact that some patients with LHON show improvements in visual function implies that retinal ganglion cells may suffer a reversible functional impairment, which agrees better with a transient exposure to putative neurotoxins, than the permanent damage that would be expected if the expression was solely due to genetic factors. Finally, occupational pesticide exposure has been associated with the etiology of PD, a major sporadic neurodegenerative disease characterized by complex I dysfunction. ${ }^{41-43}$ In particular, rotenone, a well-characterized and naturally occurring complex I inhibitor commonly used as an herbicide and pesticide, has been successfully used to model some of the major neurodegenerative features of PD in the rat. ${ }^{44}$ Current data also indicate that pathogenic LHON mutations and rotenone could have a common mechanism of action. While it has been proposed that the mutations induce structural changes that impair the access of the membrane-embedded electron carrier ubiquinone to its reduction site in complex $\mathrm{I},{ }^{38}$ this is a mechanism that is widely documented for class A complex I inhibitors such as rotenone (Figure 2) ${ }^{45}$ Thus, impaired reduction of ubiquinone by rotenone and probably also by the pathogenic LHON mutations facilitates electron leak and free radical formation at complex I (Figure 3). ${ }^{26,45,46}$

Finally, recent evidence highlights the complexity of the mechanisms mediating neurodegeneration in the retina when the role of environmental factors is considered. In in vitro experiments, it has been shown that mitochondria derived from isolated transformed rat ganglion cells show very low increases in superoxide production upon exposure to rotenone, compared with brain-derived mitochondria. ${ }^{47}$ However, when exposed to rotenone, primary rat retinal cell cultures including neuroglia show significant increases in superoxide production and disruption of glutamate reuptake in a concentration-dependent manner. ${ }^{48}$ Neuron-glia interactions seem to be relevant in neurodegeneration. These interactions provide compelling evidence that the pathobiology of ganglion cells should be studied within their intact neural circuitry, which mandates the use of in vivo models. In summary, LHON seems to be a multifactorial disease, the penetrance of which is strongly influenced by environmental factors. It is likely that this etiologic picture is similar to that of the more common neurodegenerative diseases.

\section{Rodent model induced by intravitreal rotenone}

Zhang and colleagues ${ }^{49}$ were the first to describe the retinotoxic effects of the mitochondrial complex I inhibitor rotenone on the microstructure of the mouse retina. Their experiments suggested that retinal ganglion cells display a particular sensitivity to mitochondrial dysfunction and served as a basis to develop a model of optic neuropathy in vivo with the properties presented below.

\section{Accuracy}

The model is unique because it features retinal neurodegeneration selective to the ganglion cells and their processes. After rotenone infusion, evidence of degeneration is restricted to the ganglion cell layer (GCL) and retinal nerve fiber layer (RNFL). These effects highlight the relevance of environmental mitochondrial toxicity in neurodegeneration, in particular of that based on disruption of the ETC at the level of complex I. This mechanism resembles the primary defect associated with the presence of pathogenic LHON mutations. In addition, the model has been further developed to yield data on the functional, structural, and biochemical dimensions, all of which reveal that the abnormalities elicited by rotenone resemble those observed in patients with LHON (Table 1). ${ }^{49-55}$ 


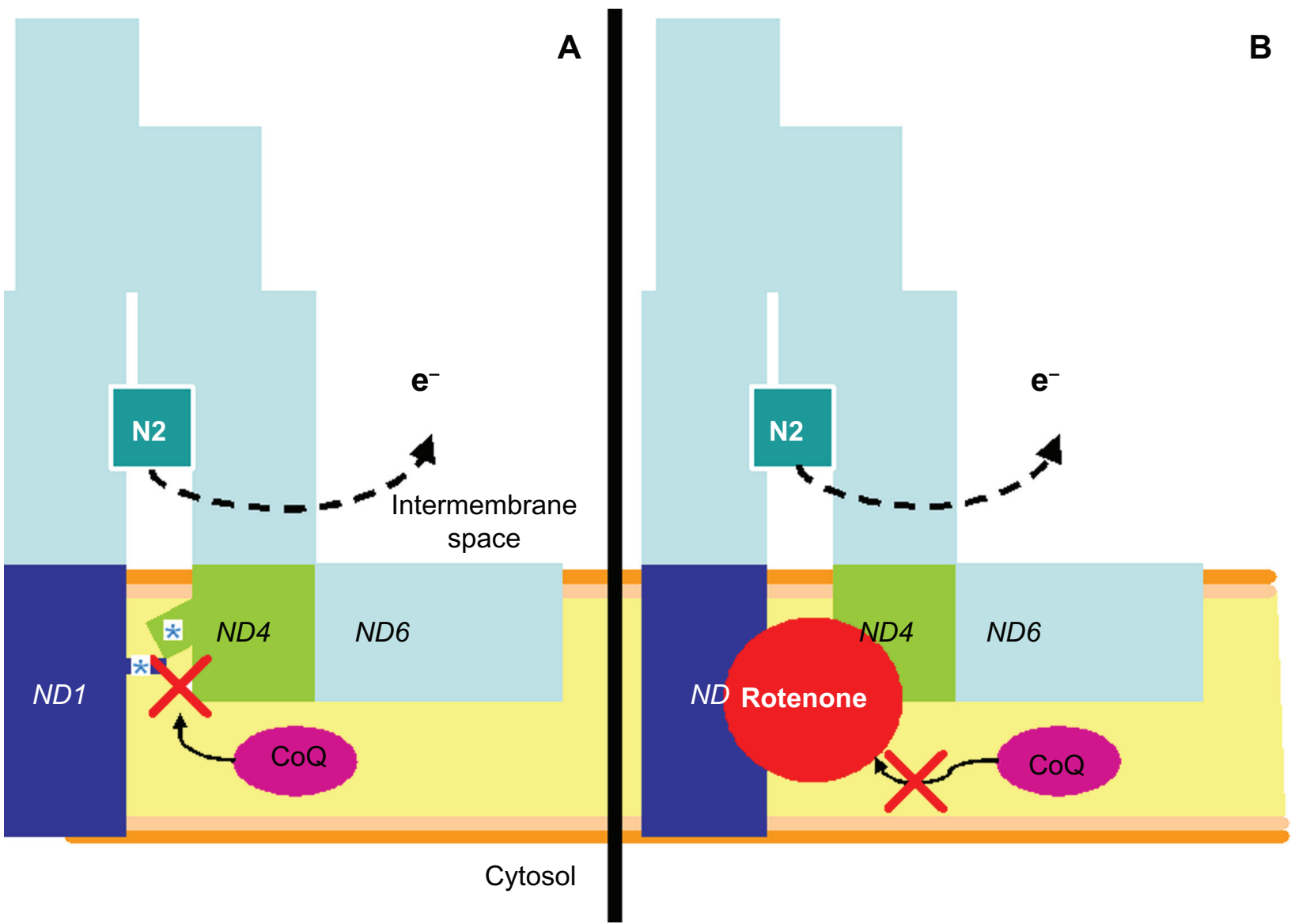

Figure $2 \mathrm{~A}$ similar mechanism of complex I dysfunction induced by pathogenic LHON mutations and rotenone. A) LHON pathogenic mutations occur in mitochondrial genes encoding for the internal membrane-embedded complex I subunits NDI, ND4 and ND6. These subunits are located in the interface with the peripheral, nuclear-encoded PSST and $49 \mathrm{kDa}$ subunits that form a ramp that allows the electron carrier ubiquinone (CoQ) to reach the iron-sulfur center N2 at its reduction site within complex I. LHON mutations are believed to induce a conformational change that prevents CoQ from reaching its reduction site (asterisks). B) Rotenone has been demonstrated to impair $\mathrm{CoQ}$ reduction by blocking its access to the reduction site. High energy electrons ( $\mathrm{e}^{-}$) not used in CoQ reduction react with oxygen molecules to form superoxide ions, thus increasing oxidative stress.

Abbreviations: CoQ, coenzyme Q; LHON, Leber's hereditary optic neuropathy

\section{Neurochemical effects}

Elucidation of the mechanisms underlying retinal neurodegeneration in LHON has been attempted by studying the biochemical changes in vitro using respiration or enzymatic studies. ${ }^{4,25,38}$ These changes have been analyzed in blood cells, skeletal muscle, fibroblasts, and, very rarely, in nervous tissue. With these approaches, a direct association between complex I dysfunction, bioenergetic failure, and neurodegeneration in LHON has been difficult to establish. ${ }^{25}$ While clinical studies are critical for the development of experimental therapeutics, the use of the rotenone animal model of retinal degeneration could reveal a path to mechanistic elucidation, but most importantly could help making progress in development of therapeutics. A major advantage of the rotenone model is that traditional biochemical analyses for investigating mitochondrial function can be carried out directly on retinal tissue. It is, for example, a powerful tool to detect retinal changes in oxidative stress and energy metabolic capacity in situ,,$^{50,53}$ two aspects that have been poorly characterized in specimens from LHON patients so far. In this model, the adverse neurochemical effects of rotenone have been demonstrated in the retina in situ, where twofold increases in superoxide levels were observed 24 hours after rotenone injection..$^{53}$ Remarkably, retinal superoxide levels were significantly increased in the GCL, but were minimal in outer retinal layers (Figure 4A and 4B). In addition, rotenone was shown to induce a 2.4-fold increase in the number of apoptotic cells in the GCL, which suggests that retinal ganglion cells are particularly susceptible to the neurotoxic effects of rotenone. Retinal oxidative stress is difficult to assess directly in humans. However, patients with LHON have shown signs of increased oxidative damage in whole blood and leukocytes. ${ }^{56-58}$

Further studies of this model have also provided insights into the link between oxidative stress, excitotoxicity, and 


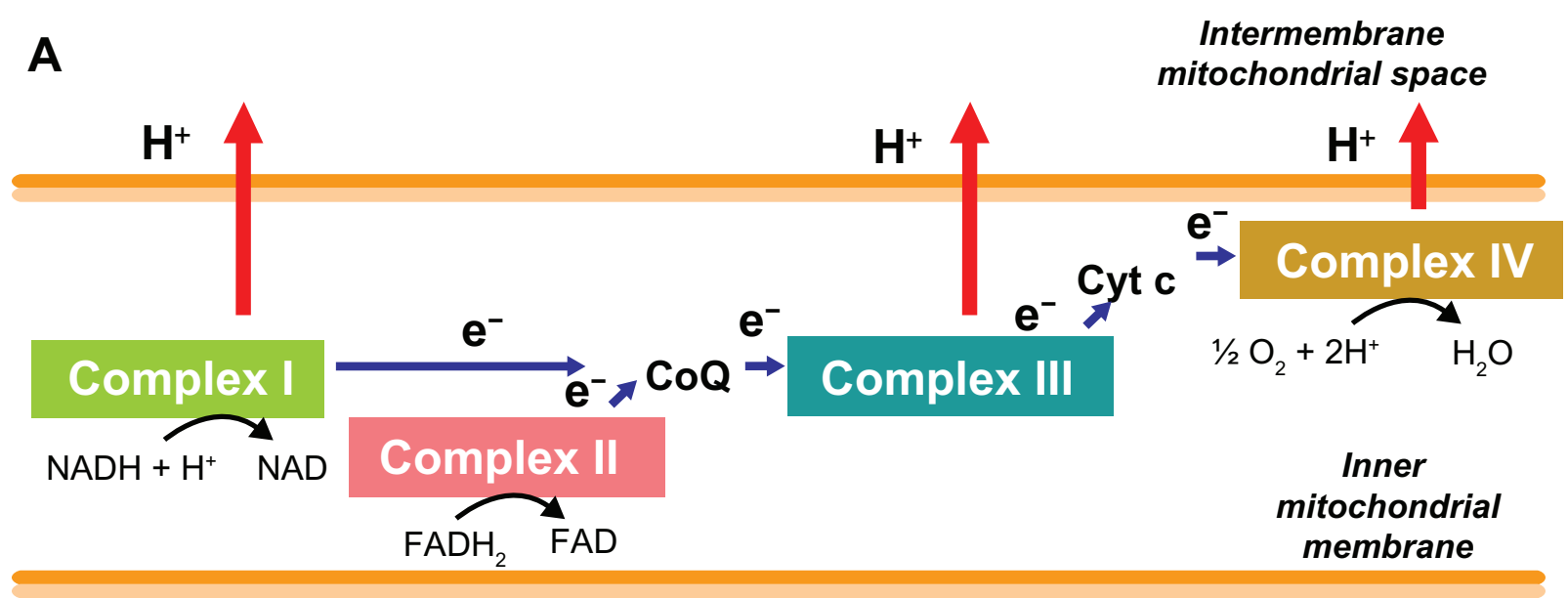

B

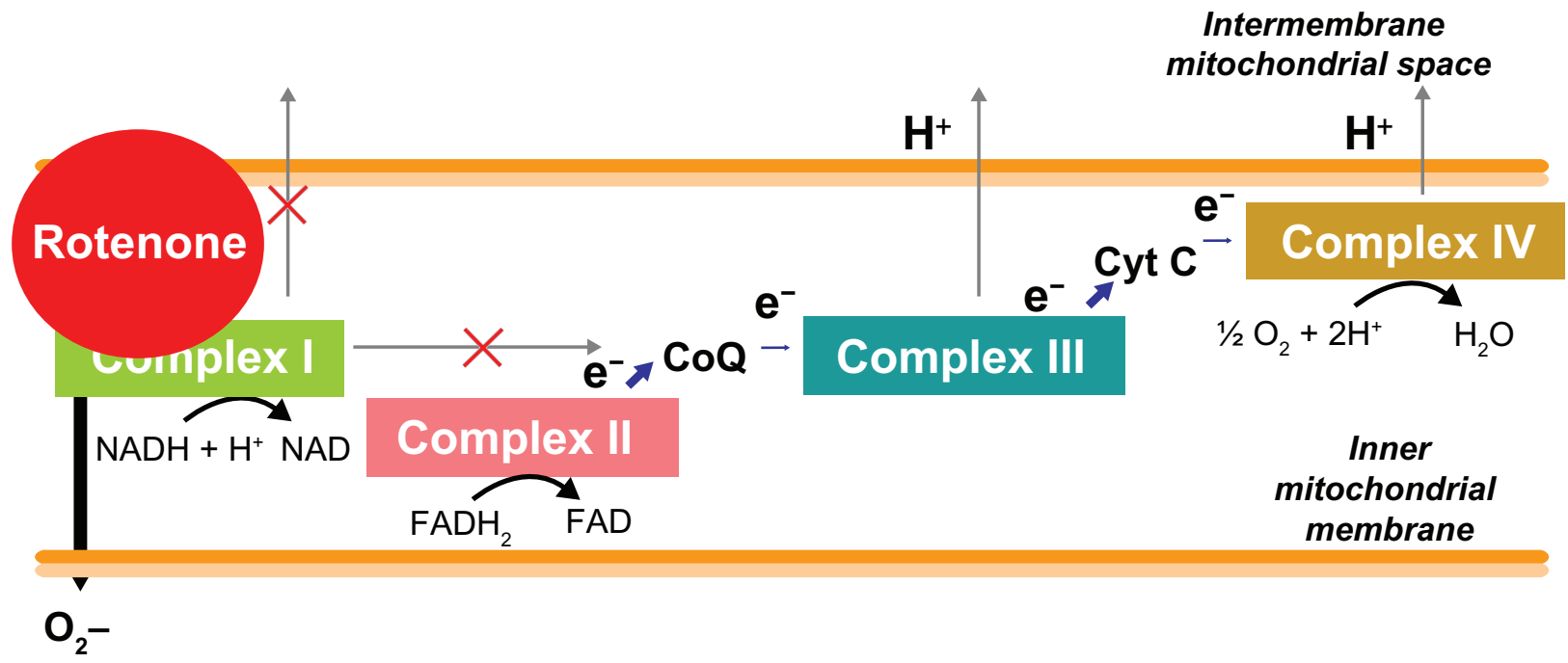

Figure 3 Disruption of the electron transport chain by rotenone. A) Normally electron donors ( $\mathrm{NADH}$ and FADH $\left.{ }_{2}\right)$ reduce mitochondrial complex I or II. Electrons (e-) are sequentially transferred to ubiquinone (CoQ), complex III, cytochrome $c(C y t c)$ and complex IV (cytochrome oxidase). As this electron transfer occurs in a tightly regulated fashion, the energy released from each redox reaction is used to pump protons $\left(\mathrm{H}^{+}\right)$into the intermembrane space to generate an electrochemical gradient that activates the enzyme ATP synthase. B) However, inhibition of complex I by rotenone impairs the entry of electrons into the respiratory chain and not only reduces the potential for energy formation, but also generates an unregulated electron leakage that promotes the formation of highly neurotoxic reactive oxygen species, in particular, superoxide $\left(\mathrm{O}_{2}^{-}\right)$.

Abbreviations: ATP, adenosine triphosphate; CoQ, coenzyme Q.

neurodegeneration. For example, GCL increases in apoptosis and oxidative stress have paralleled ganglion cell body and fiber degeneration, and these effects have been prevented by the selective blockade of the $N$-methyl-D-aspartate receptor $(\mathrm{NMDAR})^{53}$ or antioxidants, ${ }^{51,55}$ implicating calcium overload and oxidative damage as mediators and most probably precursors of neurodegeneration. The fact that NMDAR blockade with the non-competitive antagonist, memantine, was able to prevent biochemical and structural retinal damage induced by a mitochondrial toxin in a dose-response manner, suggests tight coupling between calcium homeostasis and energy metabolism, as indicated by in vitro studies. ${ }^{59}$ It was hypothesized that prevention of intracellular calcium overload in pathologically activated NMDAR could reduce energy expenditure by preventing uncontrolled depolarization, ${ }^{60,61}$ and activation of calciumdependent enzymes. ${ }^{62}$ These effects secondary to NMDAR blockade would allow the expression of mechanisms to enhance neuronal survival, including the assembly of functional respiratory enzymes. ${ }^{53}$ Of note, an early electron microscopy study of LHON human retinal tissue reported the presence of 
Table I Comparative features of Leber's hereditary optic neuropathy and the animal model of rotenone-induced optic neuropathy

\begin{tabular}{|c|c|c|}
\hline & Leber's hereditary optic neuropathy & Rotenone-induced optic neuropathy \\
\hline Course & $\begin{array}{l}\text { - Acute to subacute onset (weeks to months) } \\
\text { - Permanent damage in the majority of cases }\end{array}$ & $\begin{array}{l}\text { - Rapid onset of neurodegeneration (hours to days) } \\
\text { - Permanent damage }\end{array}$ \\
\hline Etiology & - mDNA mutations & - Rotenone \\
\hline Mechanism & $\begin{array}{l}\text { - Abnormal expression of transmembrane } \\
\text { (NDI, ND4 and ND6) complex I subunits }\end{array}$ & $\begin{array}{l}\text { - Blocks entry of ubiquinone into ramp connecting } \\
\text { the transmembrane (NDI, ND4 and ND6) and } \\
\text { peripheral sectors of complex I }\end{array}$ \\
\hline Oxidative stress & $\begin{array}{l}\text { - Increased blood oxidative stress } \\
\text { - Increased leukocyte DNA oxidative damage } \\
\text { - Increase in oxidative stress-induced } \\
\text { lymphocyte apoptosis }\end{array}$ & $\begin{array}{l}\text { - Increased superoxide production confined to } \\
\text { ganglion cell layer (GCL) }\end{array}$ \\
\hline $\begin{array}{l}\text { Metabolic impairment } \\
\text { and excitotoxicity }\end{array}$ & $\begin{array}{l}\text { - Intracellular calcium inclusions } \\
\text { - Swollen mitochondria and ganglion cells } \\
\text { - Decreased complex I activity and oxidative } \\
\text { phosphorylation } \\
\text { - Decreased NADH/NAD ratio }\end{array}$ & $\begin{array}{l}\text { - Early increased metabolic capacity } \\
\text { - Late decreased metabolic capacity } \\
\text { - Neurodegenerative effects prevented by NMDA } \\
\text { receptor blockade }\end{array}$ \\
\hline Early structural effects & - RNFL edema & - IPL edema \\
\hline Late structural effects & $\begin{array}{l}\text { - Selective and massive degeneration of the } \\
\text { RNFL and GCL } \\
\text { - } 95 \%-100 \% \text { atrophy of papillomacular bundle } \\
\text { - GCL pyknosis } \\
\text { - Optic nerve atrophy, gliosis and demyelination } \\
\text { - Mild IPL atrophy }\end{array}$ & $\begin{array}{l}\text { - Selective and massive degeneration of the RNFL } \\
\text { and GCL } \\
\text { - } 50 \% \text { atrophy of peripapillary fibers } \\
\text { - } \mathrm{GCL} \text { apoptosis } \\
\text { - Optic nerve atrophy and gliosis } \\
\text { - IPL atrophy }\end{array}$ \\
\hline Functional deficits & $\begin{array}{l}\text { - Decreased visual acuity, dyschromatopsia } \\
\text { and contrast sensitivity } \\
\text { - Preserved pupillary light reflex } \\
\text { - Transynaptic structural evidence of retinal } \\
\text { deafferentiation }\end{array}$ & $\begin{array}{l}\text { - Decreased contrast sensitivity } \\
\text { - Preserved pupillary light reflex } \\
\text { - Transynaptic metabolic evidence of retinal } \\
\text { deafferentiation } \\
\text { - Visual deficits highly correlate with structural } \\
\text { damage }\end{array}$ \\
\hline
\end{tabular}

Abbreviations: DNA, deoxyribonucleic acid; IPL, inner plexiform layer; GCL, ganglion cell layer; RNFL, retinal nerve fiber layer.

swollen mitochondria and calcium-containing inclusions, ${ }^{63}$ which also suggest a link between mitochondrial dysfunction and excitotoxicity-mediated retinal degeneration, but this association has been poorly characterized in human tissue. Retinal enzyme histochemistry (eg, complex I or cytochrome oxidase activity) has allowed clear visualization of regions rich in mitochondria, like the GCL and RNFL. These methods differentiate retinal regions with high mitochondrial content from those with less mitochondrial density, like the inner and outer nuclear layers. ${ }^{49,51,52,54,55}$ Changes in energy metabolic capacity after rotenone administration have been characterized in the animal model by cytochrome oxidase enzyme histochemistry. Cytochrome oxidase is the terminal enzyme of the respiratory chain and is a key enzyme in energy metabolism. ${ }^{64}$ Cytochrome oxidase activity accurately reflects the responses to increased energetic demands within neurons, and is widely use as a marker of aerobic metabolic capacity. ${ }^{65}$
At 24 hours after intravitreal rotenone administration, both the inner plexiform layer and the optic nerve displayed $18 \%$ and $51 \%$ increases in cytochrome oxidase activity, respectively. ${ }^{55}$ The inner plexiform layer and the optic nerve contain the dendrites and axons of retinal ganglion cells, and are known to have a high density of mitochondria. ${ }^{66}$ These retinal increases in cytochrome oxidase activity after rotenone exposure could represent adaptations of the mitochondrial respiratory machinery to increased energetic demands secondary to excitotoxicity, oxidative stress and energy depletion. In contrast, the GCL itself shows no changes in cytochrome oxidase activity after 24 hours, but it shows a $30 \%-40 \%$ reduction after 15 days. ${ }^{52,55}$ Notoriously, retinal decreases in energy metabolism capacity after rotenone were found to correlate with histologic retinal damage and with impairments in behaviorally assessed visual function. ${ }^{51}$ 

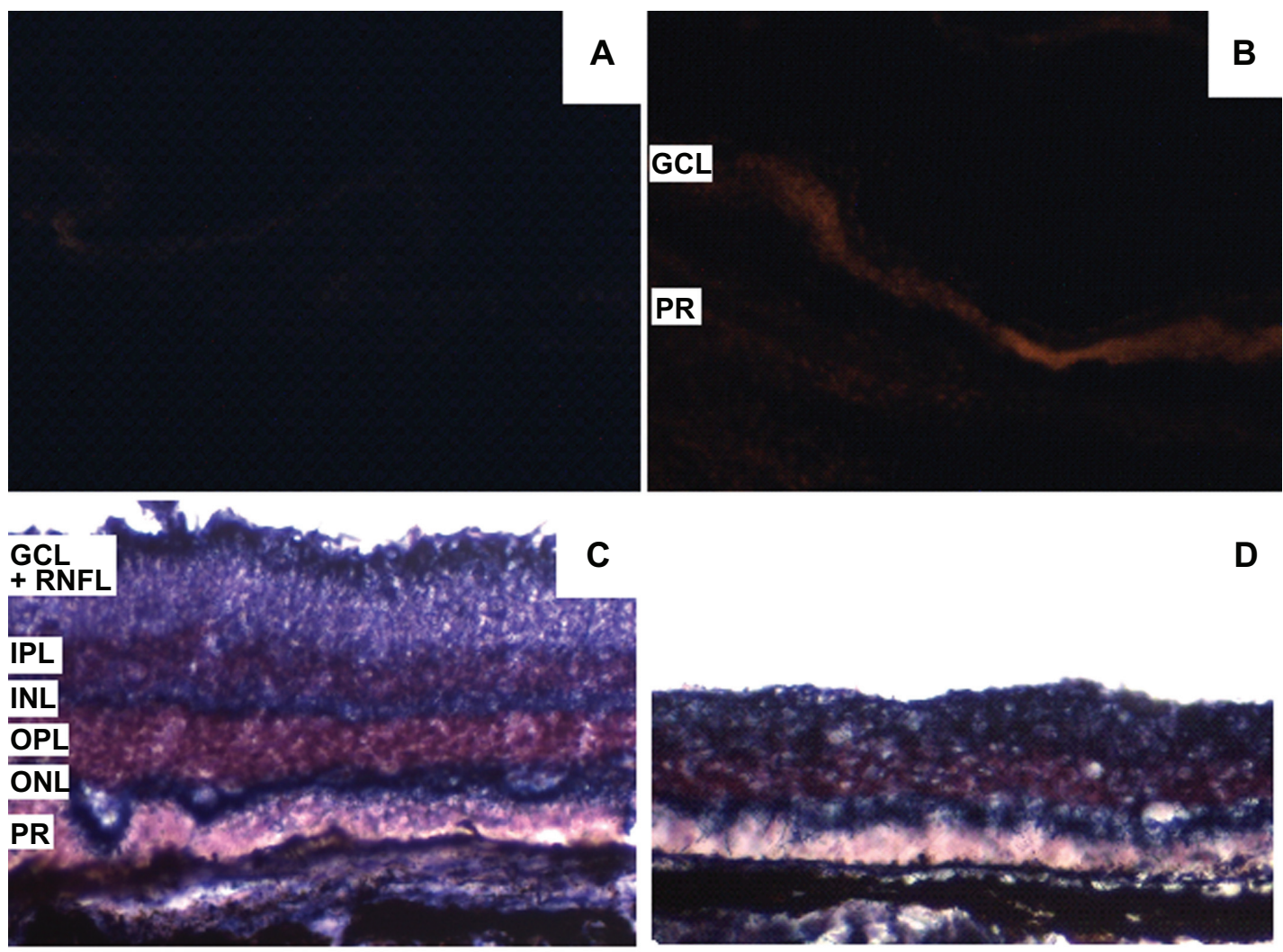

C

D
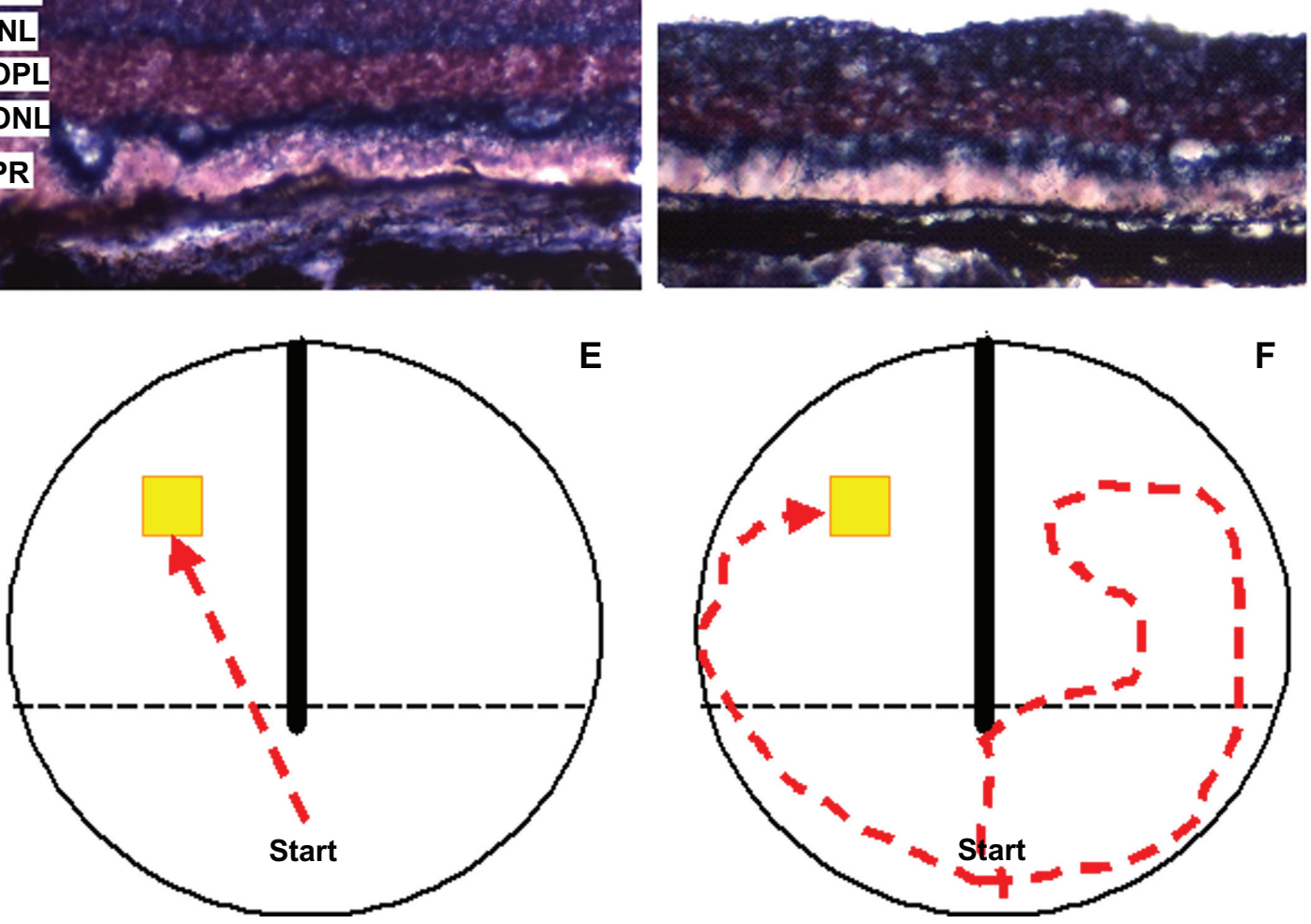

E

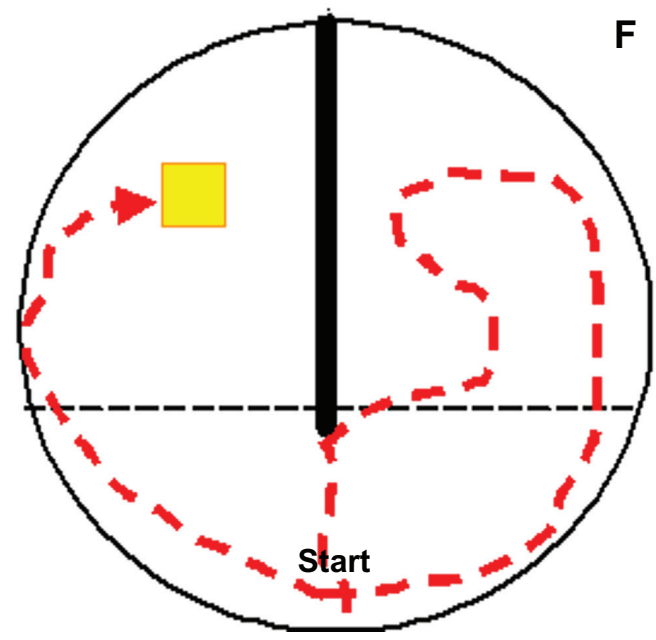

Figure 4 Neurochemical, structural and functional effects of rotenone in the rat retina. Sagittal retinal sections stained with the superoxide probe dihydroethidium show a massive increase in the free radical signal in rotenone-treated eyes B) compared to vehicle-treated controls $\mathbf{A})$ under epifluorescence microscopy (I0 $\times$ ). After several days, rotenone-treated retinas D) display a visible decrease in thickness, compared with control C). This change occurs mainly at the expense of the retinal nerve fiber layer (RNFL) and ganglion cell layer $(\mathrm{GCL})$ and is detectable with a NADH dehydrogenase enzyme histochemistry method. Panels $E$ and $F$ show diagrams of typical swimming patterns in an apparatus designed to test visual function. The visual ability of subjects treated with intravitreal rotenone is severely impaired. This change is manifested behaviorally with prolonged, erratic, and hesitant trajectories and incorrect compartment entrances during a task involving the visual localization of an escape platform F). Such swimming patterns contrast with the rapid and straight trajectories of control animals $\mathbf{E}$ ).

Abbreviations: GCL, ganglion cell layer; IPL, inner plexiform layer; INL, inner nuclear layer; OPL, outer plexiform layer; ONL, outer nuclear layer; PR, photoreceptor layer; RNFL, retinal nerve fiber layer.

\section{Structural effects}

The morphologic changes observed in the rotenone model of retinal degeneration are strikingly similar to those described in patients with LHON. Just as structural retinal changes in
LHON are time-dependent, rotenone induces a progressive retinal degeneration in the mouse and rat retina that has been stereologically characterized. Early LHON features peripapillary retinal nerve fiber layer (RNFL) pseudoedema. ${ }^{67}$ 
In the animal model, this is mimicked by early thickening of about $11 \%$ in the peripapillary inner plexiform layer only 30 minutes after rotenone injection, without further changes in other retinal layers. ${ }^{54}$ Furthermore, in LHON, optic nerve atrophy progresses over several months until it is almost universal. Neuropathologic studies of LHON have consistently demonstrated massive degeneration of the retinal ganglion cell layer and of the optic nerve without signs of inflammation in late phases of the disease. ${ }^{63,68}$ The retina shows peripheral cystic degeneration, with about $95 \%$ axonal loss in the optic nerve. The ganglion cell layer degeneration is more prominent in the papillomacular bundle region, but is not, by any means, confined to this region. ${ }^{69}$ Occasional pyknotic nuclei can be detected in the remaining GCL. A mild degree of inner nuclear layer degeneration has also been reported, but in general, outer retinal layers are usually spared. The optic nerve shows diffuse atrophic nerve fiber bundles, with demyelination, gliosis, thickening of the pial septa, but no signs of inflammation. ${ }^{68}$ All these neuropathologic changes have a counterpart in the peripapillary rodent retina. While, a distinct papillomacular bundle is not readily evident in the rodent retina, severe changes are found within $200 \mu \mathrm{m}$ radial to the optic disc after rotenone injection (Figure 5). ${ }^{49,54,55}$

First there is an acute-to-subacute onset of degeneration that takes place between 0.5 and 1 hour after injection, and evolves over several hours to reach a plateau at 24 hours. At 1 hour, a $32 \%$ decrease in the combined thickness of the GCL and RNFL compared with the control value is already observed. The thinning of these two layers progresses to $42 \%$ at 24 hours and reaches $58 \%$ on day 17 (Figure 4C and 4D). The thickness reduction is dose-dependent with half-dose rotenone $(100 \mu \mathrm{g} / \mathrm{kg})$, inducing a reduction of only $5 \%$ at 24 hours. Also at 24 hours, the thickness reduction for the GCL alone is $18 \%$, but the thickness reduction of the RNFL is $89 \%$, which highlights the marked vulnerability of nerve fibers to the neurotoxic effects of rotenone. Further histopathologic changes observed at 24 hours within the peripapillary GCL include a $21 \%$ decrease in cell density, with preferential decreases of neurons with the largest somata, presence of pyknotic cells denuded of processes, remaining processes with retraction bulbs and fibers with decreased synaptic spines. ${ }^{50}$ Evidence of neurodegeneration in layers containing ganglion cell processes is also already present at 24 hours. Axon bundles approaching the optic disc show a 50\% decrease, and the zones of granular lines in the inner plexiform layer disappear. At 72 hours the most striking change is the presence of severe optic nerve vacuolation and gliosis that replaces nerve bundles on transverse section, also similar to that observed in LHON. The number of vacuoles shows a strong negative correlation with the number of remaining ganglion cells $(-0.89, P<0.05) .{ }^{50}$ Finally, 17 days after rotenone injection the combined thickness of the GCL + RNFL shows a $58 \%$ decrease compared with the control value, whereas the GCL cell density is reduced by almost $30 \%$. At this late time point a nearly $50 \%$ decrease in inner plexiform layer thickness is also observed. ${ }^{51,52}$

\section{Functional effects}

The structural similarities between LHON and the animal model of optic neuropathy induced by rotenone also have a functional counterpart. LHON is usually characterized by severe and permanent visual impairment. At onset, patients report painless blurred vision unilaterally, with the second eye involved within a few weeks or months. ${ }^{31}$ There is visual field loss consisting of an enlarged blind spot that progresses and involves central vision producing a large centrocecal scotoma, within the first four to six weeks. ${ }^{18}$ These clinical deficits are paralleled by early desynchronization, delay, and amplitude reduction of visual evoked potentials, which are extinguished in the late atrophic phase. Although visual acuity changes are the most noticeable ones in LHON, progressive dyschromatopsia and deficits in illuminance contrast sensitivity are also major features of the disease. ${ }^{70-72}$ Some patients report pain in an affected eye or on eye movements, and a minority experience worsening of visual disturbance with physical exertion. ${ }^{73}$ Visual dysfunction has been successfully modeled using rotenone-induced optic neuropathy of the rat. ${ }^{51,52} \mathrm{~A}$ protocol has been developed to assess retinal neurodegenerative changes at the functional level focusing on behaviorally meaningful parameters. Simple two-choice discrimination tasks combined with the psychophysical method of limits can be used to evaluate a number of visual submodalities including acuity, and spatial and temporal contrast sensitivity. ${ }^{74-76}$ Bias introduced by olfactory and somatosensory input can be controlled in apparati that maximize reliance on visual information, such as water mazes (Figure 4E and 4F). These sorts of behavioral tests are highly sensitive to minute changes in visual function in rats treated with intravitreal rotenone. ${ }^{51,52}$ For example, rotenone induces elevations in the dark-adapted illuminance sensitivity threshold ranging from 2 to $3.8 \mathrm{Log}$ illuminance units. Such changes correlate with discrete (eg, percentage of correct choices) and continuous (eg, latency to solve the task) ancillary measures of behavioral performance. ${ }^{51}$ Even more importantly, functional impairment correlates with structural indexes 
A

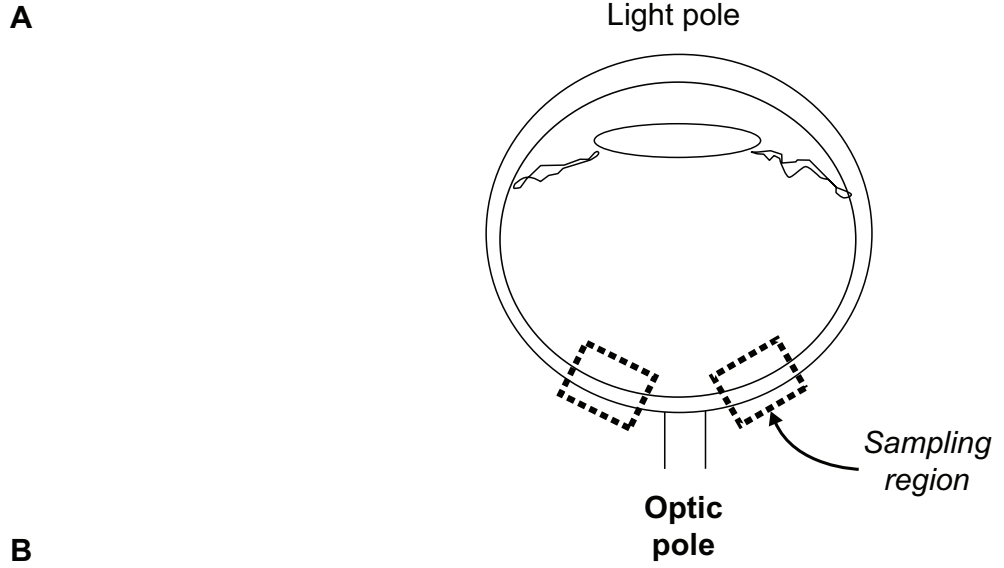

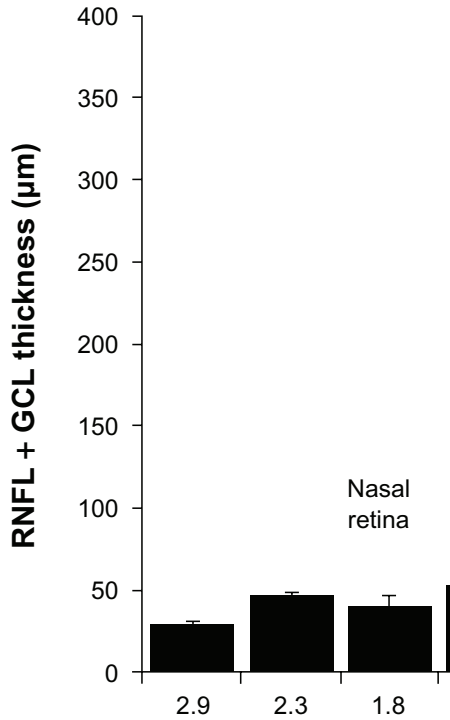

C

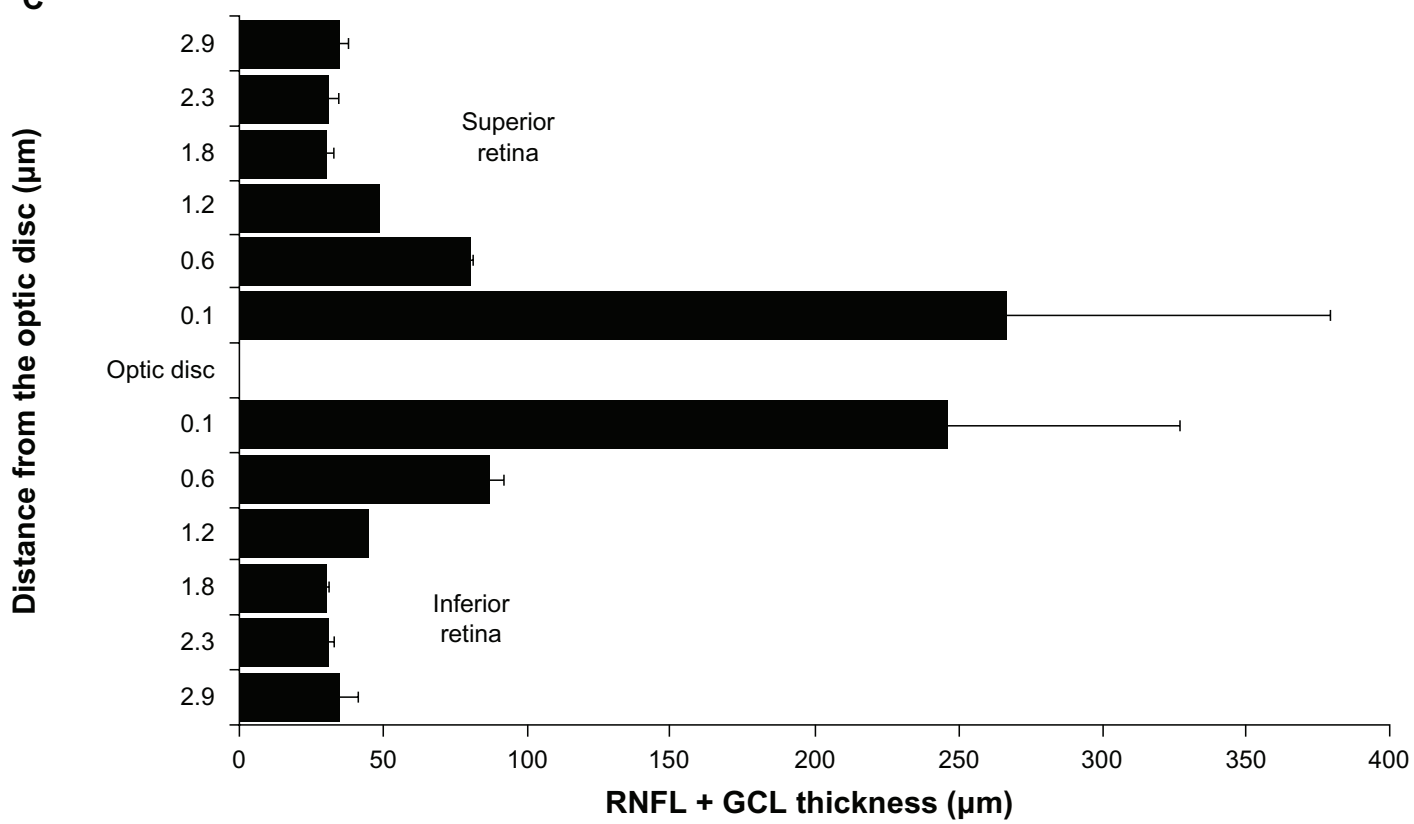

Figure $\mathbf{5}$ Sampling strategy for retinal thickness, and retinal thickness per quadrant in the adult male rat. A) Samples of retinal images are systematically obtained from sagittal eyeball sections. These samples are located within $200 \mu \mathrm{m}$ of the optic disc. In coronal eyeball sections B) and C) retinal thickness in the periphery decreases as a function of the distance to the optic disc, but there are no thickness differences between quadrants. 
of retinal degeneration $(-0.91, P<0.01)$ and of retinal mitochondrial metabolic capacity $(-0.64, P<0.01)$. For example, each one second increase in mean latency to solve the behavioral task predicts an approximate $4 \mu \mathrm{m}$-decrease in GCL + RNFL thickness on an individual basis. Thus, the model allows structure-function relationships with potential value for drug screening to be identified.

Two additional functional peculiarities are also common to both LHON and the animal model of optic neuropathy. Rotenone-treated mice and rats have no alteration of the pupillary light reflex, ${ }^{54}$ which is also observed clinically, even among those LHON patients with the most severe visual loss. ${ }^{77}$ In addition, the central visual pathway of patients with LHON has been reported to show signs of deafferentiation, including degeneration of the chiasm, optic tracts, lateral geniculate nucleus, and geniculocalcarine fibers. ${ }^{68}$ In fact, in LHON patients, the lateral geniculate nucleus, which is the main central recipient of retinal fibers, shows cell atrophy, cell loss, and gliosis in all six layers, with no evidence of inflammation. These findings support a process of anterograde transneuronal degeneration in LHON. Similarly, functional effects of visual deafferentiation can be found transynaptically in relay centers of the central visual pathway in the animal model. Subjects treated with rotenone show not only decreased metabolic capacity in the retina, but also in the superior colliculus (the main recipient of retinal fibers in rodents), the lateral geniculate nucleus, and primary visual cortex, whereas a compensatory increase in metabolic activity is observed in the secondary visual cortex compared with control values. ${ }^{51}$ These findings are significant because they suggest that neurodegeneration can be assessed at a systems level. The induction of retinal damage has functional effects in distant brain regions which can be studied independently of a direct effect of the neurotoxin. The ability to study such expected changes could be also of great relevance to the study of patterns of neurodegeneration at a network level in AD and other major neurodegenerative disorders.

\section{Efficiency}

Using the retina to study neurodegeneration and neuroprotection combines the advantages of a relatively isolated in vitro system with the biologic relevance of an in vivo system. The eye provides a local system ideal for toxicologic studies. It provides easy access to the neural tissue in the retina, and enables physically restriction of the neurotoxic effects of substances such as rotenone to a part of the central nervous system with a well-characterized neural circuitry. In the model of optic neuropathy, the degree of degeneration induced by local rotenone administration (ie, intravitreal), has been shown to be dose- and time-dependent, and a single rotenone injection is able to induce retinal neurodegeneration in a very reduced amount of time. This is in marked contrast with the repeated systemic injections over several days or weeks needed to achieve the desired effect in other in vivo neurotoxicologic models of degeneration induced by mitochondrial dysfunction. ${ }^{44,78}$ In fact, the rotenone dose effective at inducing retinal degeneration (100-200 $\mu \mathrm{g} / \mathrm{kg}$ ) is at least 10 times lower than doses required for inducing neurodegeneration in the nigrostriatal system after systemic administration, which usually range from 2 to $3.5 \mathrm{mg} / \mathrm{kg}$. The effective rotenone intravitreal dose is instead similar to those used for local infusion into the nigrostriatal system. ${ }^{79,80}$ The use of rotenone to induce mitochondrial dysfunction is not technically demanding and is relatively inexpensive. Also, using the visual system for neurotoxicologic studies is highly efficient because it allows within-subject control designs. In such studies, one eye can be used to test the experimental condition while the contralateral eye can be used as an internal control for biologic variability. Also, the study of the metabolic properties of the retina (ie, in situ oxidative stress, ETC activity, cell death) can be achieved in frozen samples in which case no animal perfusion is necessary. Finally, because of its relatively small volume, eyeball and retinal tissues can be dissected and processed more rapidly than specific brain regions or whole brains.

\section{Sensitivity and versatility}

As mentioned earlier, a combination of mitochondrial-related tissue histochemistry, stereology, and psychophysical testing has been highly sensitive to the neurodegenerative changes induced by rotenone. In addition, these methods have demonstrated a high correlation between pathologic changes at different levels of analysis and they are also sensitive to the protective effects of candidate therapeutics as detailed below. The model has also been used in concert with fluorescent intraneuronal reporter genes to track ultrastructural changes elicited by rotenone. ${ }^{50}$ Again, due to the accessibility to the retina, these technologies could provide a means to track structural neurodegenerative changes over time in vivo, if further combined with adequate imaging tools such as adaptive optics ${ }^{81}$ or scanning laser opthalmoscopy. ${ }^{82}$ Finally a major advantage of a model of neurodegeneration based on administration of an exogenous neurotoxin is that it could be an important complement to models of neurodegeneration based on genetic knockouts or manipulations to modify gene expression, ${ }^{27,83-85}$ which could allow mechanistic studies of 
the pathogenic synergism of environmental neurotoxins and inherited genetic defects.

\section{Utility in mechanistic elucidation}

The rotenone model of optic neuropathy provides an ideal pathophysiologic context for testing the efficacy of candidate therapeutic interventions with a mitochondrial mechanism of action. The major contribution of studies with this model is the proof-of-principle that agents that modulate the function of the ETC and interfere with main mediators (oxidative stress, energy depletion) and events (mitochondrial dysfunction, excitotoxicity) of degeneration are effective at preventing cell loss and neurologic impairment in vivo. This mechanistic contribution also suggests novel interventions with potential benefits that are directly relevant to patients affected by LHON, for which no effective treatment is available. As mentioned above, the model of optic neuropathy has allowed assessment of the interrelation of ETC blockade with oxidative stress, excitotoxicity, and neurodegeneration. The fact that memantine, an NMDAR antagonist, decreased oxidative stress, prevented nerve cell and nerve fiber loss, and boosted the expression of cytochrome oxidase, supports the hypothesis that neurodegeneration is mediated by a series of deleterious events including mitochondrial dysfunction, oxidative stress, energy metabolism, and calcium-induced excitotoxicity. ${ }^{53}$ The data generated with this model support the notion that these events exacerbate each other, leading to a vicious cycle of neurodegeneration. Specifically, it was demonstrated that oxidative stress and neural damage initiated in mitochondria (ie, through complex I inhibition) can be prevented by blockade of an ion channel permeable to calcium in the cell membrane (ie, NMDAR). Thus, it is possible that suppression of one of the deleterious events is able to reduce the reciprocal influence on others, preventing the cascade that leads to neurodegeneration. A link between energy metabolism and NMDAR activity is further supported by recent evidence of genetic coregulation of NMDAR and cytochrome oxidase subunits by the same transcription factor. ${ }^{86}$ These data suggest that NMDAR blockade induces a series of watershed effects that allow for compensatory intracellular changes associated with neuronal survival, including up-regulation of respiratory chain or antioxidant enzymes. If environmental etiologic factors of neurodegeneration (eg, rotenone and other mitochondrial toxins) affect mitochondrial function, mitochondria represent the most likely entry point into this cascade of neurodegenerative events and consequently the target that most likely will produce endurable neuroprotective effects. The data generated in the model of optic neuropathy highlight the relevance of mitochondrial function and bioenergetics for neuronal survival. The ETC and oxidative phosphorylation seem to be the most elementary mechanisms supporting neuronal function. The integrity of these processes is fundamental for neuronal survival and, because of their role in redox balance and adequate energy production, both are prerequisites for intra- and extra-mitochondrial functions that preserve neuronal homeostasis.

\section{Utility as a screening tool for new therapies Methylene blue}

The model of optic neuropathy has been successfully used to demonstrate the efficacy of pharmaceutical grade (USP) methylene blue [3,7-bis(dimethylamino)-phenazathionium chloride $\left.\left(\mathrm{C}_{16} \mathrm{H}_{18} \mathrm{~N}_{3} \mathrm{ClS}\right)\right]$ (MB) as a mitochondrial neuroprotective intervention. $\mathrm{MB}$ is an FDA-grandfathered potent redox diaminophenothiazine with high bioavailability to mitochondria and has autoxidizable properties that emulate the action of ubiquinone (Coenzyme Q) in the ETC. MB is similar to ubiquinone in that it has an oxidation-reduction potential that is intermediate between that of endogenous electron donors (eg, NADH, $\mathrm{FADH}_{2}$ ) and oxygen. ${ }^{87,88}$ This property enables MB to act as an electron shuttle in the ETC. However, in contrast with ubiquninone, MB readily crosses the blood-brain barrier concentrating in nervous tissue, ${ }^{89,90}$ permeating through cell membranes, and localizing to mitochondria, when given by enteral or parenteral routes. ${ }^{91}$ MB localization to mitochondria and its high affinity for oxidoreductases-a property that has allowed MB use as a supravital stain-also follows from the unique redox potential of MB. In addition, imino group-containing molecules, such as $\mathrm{MB}$, are considered among the most powerful antioxidant organic compounds. ${ }^{92}$ Several studies have demonstrated that MB has a propensity to enter living, metabolically active cells, where it is capable of stimulating mitochondrial oxidative metabolism, oxygen consumption, and cell respiration. ${ }^{93-95} \mathrm{In}$ the brain, and at low concentrations, MB not only improves oxygen consumption but also increases the expression of the mitochondrial enzyme cytochrome oxidase. ${ }^{96,97}$ This effect enhances the metabolic capacity of neurons and contributes to the maintenance of bioenergetic homeostasis. Thus, it was hypothesized that MB could exert mitochondrial neuroprotection in the model of optic neuropathy via its powerful in situ antioxidant effects and its cell respiration enhancing properties. Whereas rotenone produced a noticeable 
loss of ganglion cell bodies and optic nerve fibers, MB co-administration almost totally prevented these changes in a dose-response manner. ${ }^{55}$ The neuroprotective effects of MB were also demonstrated at the functional level, inducing preservation of visual function, as measured by metabolic and behavioral parameters. ${ }^{51}$ The work with MB in the model of optic neuropathy supports the concept that in the presence of complex I inhibition, stimulation of the ETC paired with free radical-scavenging is highly efficacious at preventing the neurodegenerative effects of mitochondrial dysfunction.

Recently, a great deal of scientific and media attention has been given to $\mathrm{MB}$, after preliminary data from a Phase I clinical trial showed that it prevented cognitive deterioration in patients with $\mathrm{AD}$. Trademarked as Rember ${ }^{\circledR}, \mathrm{MB}$ was given at a dose of $60 \mathrm{mg}$ three times a day for 24 months to patients with mild to moderate $\mathrm{AD} .{ }^{98}$ After 50 weeks, there was an $81 \%$ reduction in the rate of cognitive decline compared with controls. If reproducible, this would be an effect without precedent in pharmacologic strategies to combat AD. Although these preliminary data relate to a study designed to test toxicity and not efficacy, they are promising and warrant further investigation. Importantly, the work with the animal model of optic neuropathy demonstrated that MB is able to prevent neuronal loss in a model of retinal degeneration not mediated by Tau or $\beta$-amyloid deposition. Thus, it suggests that the mechanism of action of MB could be related to enhancement of mitochondrial respiration and to its powerful antioxidant effect in the presence of a mitochondrial complex I inhibitor. This in turn indicates that prevention of oxidative stress and enhancement of mitochondrial function in vivo could be used to design new metabolic drugs against neurodegenerative disorders affecting the eye and brain. A group of phenothiazinic derivatives of MB could also share some of its neurochemical and neuroprotective effects. Derivatives such as azure $\mathrm{A}$, azure $\mathrm{B}$ or thionin vary in structure from $\mathrm{MB}$ by the absence of one, two, or three methyl groups, respectively. ${ }^{99}$ These compounds also share the imino chemical group present in $\mathrm{MB}$, which could support similar neuroprotective effects. ${ }^{92}$ Scarce experimental data are available on these compounds, and they could also be screened for neuroprotective effects in the animal model of optic neuropathy.

\section{Near-infrared light therapy}

The therapeutic use of near-infrared light (NILT) is based on the principle that certain molecules in living systems absorb photons and trigger signaling pathways in response to light. In biologic tissues, absorption and scattering of light are maximal at wavelengths below $600 \mathrm{~nm}$ and water absorbs light at wavelengths greater than $1150 \mathrm{~nm}$. Thus there is a "wavelength window" for biologic stimulation that covers the red to near-infrared light spectrum (between 600 and $1150 \mathrm{~nm}) .{ }^{100}$ Molecules that absorb near-infrared light in cells were discovered 20 years ago to be components of the respiratory chain. ${ }^{101}$ In particular, the absorption spectra of the terminal respiratory enzyme cytochrome oxidase in different oxidation states have been found to parallel the action spectra (photoresponse as a function of wavelength) of NILT. ${ }^{102}$ Thus, cytochrome oxidase is regarded as the primary cell photoacceptor of light in the red to near-infrared region of the visible spectrum. ${ }^{103}$ In neural tissue, cytochrome oxidase is the most abundant metalloprotein, and wavelength peaks in its absorption spectrum (670 and $830 \mathrm{~nm}$ ) correlate well with its peaks in catalytic activity and with ATP content in vitro. ${ }^{104}$ The neuroprotective mechanism of action of NILT has been shown to involve direct stimulation of the catalytic activity of cytochrome oxidase and upregulation of genes involved in homeostasis, including those directly related to mitochondrial energy metabolism and intrinsic antioxidant defenses. ${ }^{105,106}$ The neuroprotective effects of NILT via light emitting diodes have been characterized in the model of optic neuropathy. Similar to the effects of MB, NILT prevented the loss of retinal nerve fibers induced by rotenone and prevented the disruption of visually guided behavior and the metabolic signs of visual deafferentiation..$^{52}$ This is evidence that highly efficient neuroprotection against mitochondrial inhibition is feasible using this non-invasive and non-pharmacologic strategy. Notably, the neuroprotective effects of NILT were observed in a dose-dependent manner in structural and functional dimensions, and were accompanied by global cerebral increases in cytochrome oxidase and superoxide dismutase activities. The last finding supports a potential application of NILT for the non-invasive treatment not only of ophthalmologic but also intracranial neurologic conditions in humans.

\section{Other in vivo models}

Besides the rotenone model, animal models of optic neuropathy induced by mitochondrial dysfunction have been developed by Eells et al ${ }^{107}$ Guy et al ${ }^{27,83,84}$ and Corral-Debrinski et $\mathrm{al}^{108}$ The key features of these models, in contrast with the rotenone model discussed here, are presented in Table 2.

\section{Limitations}

Although there is a great deal of resemblance between LHON and the rotenone model, the main goal of the latter is not to reproduce faithfully LHON but to provide an accessible context of mitochondrial dysfunction to screen neuroprotective interventions. Nevertheless, as with any model, the use of rotenone 


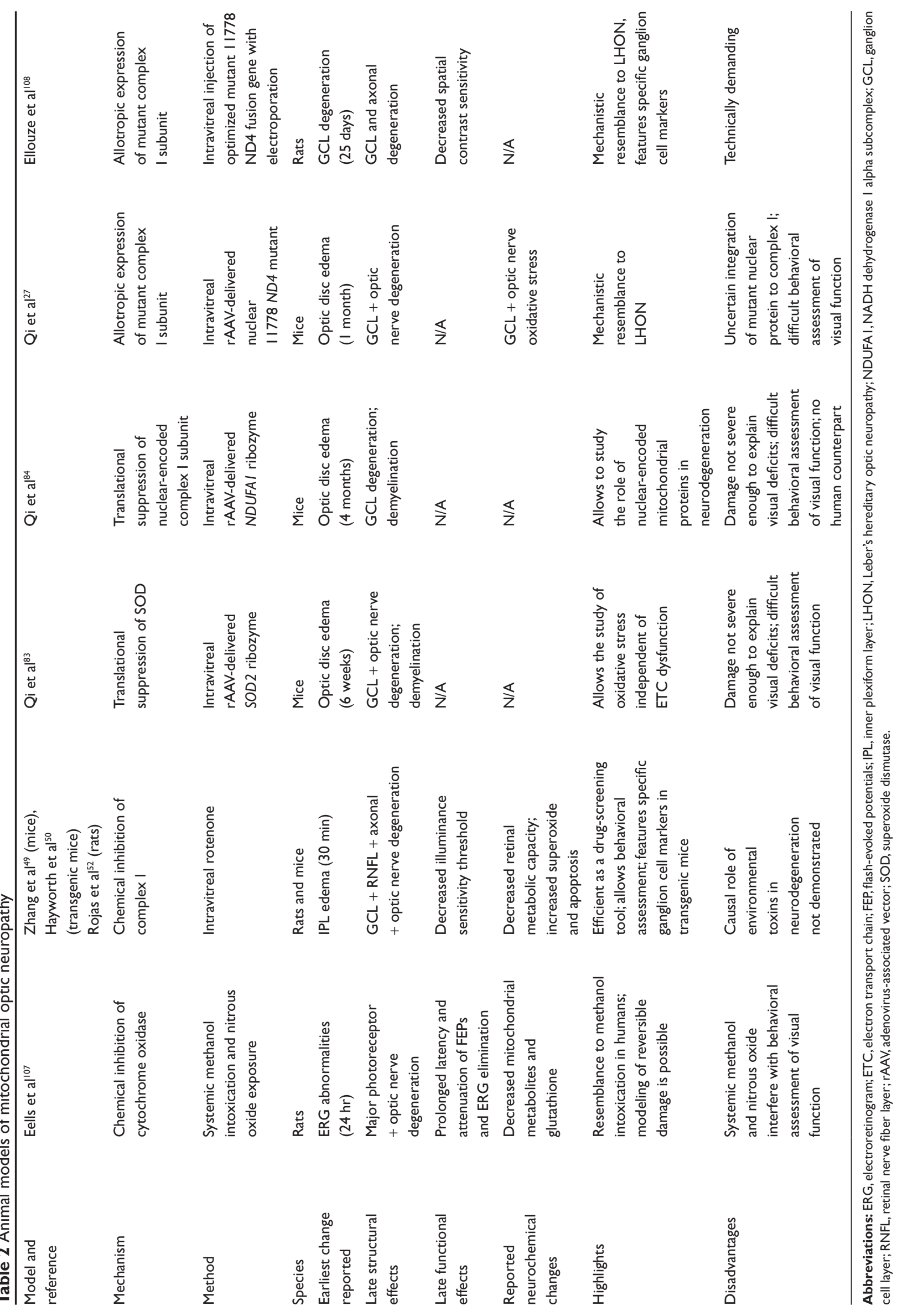


for inducing optic neuropathy has a number of limitations. The most important caveat is that it has been designed based on the hypothesis that an environmental neurotoxic insult plays a significant role in the pathogenesis of neurodegenerative disease, including LHON. Although in vitro and epidemiologic data suggest this, the existence of an environmental agent causally related to LHON remains to be demonstrated. Also, based on its current stage of development, the model does not contribute any mechanistic explanation for the variability in the expressivity and penetrance of the LHON phenotype. The only possible insight is that these are mediated by dose-response effects of putative neurotoxins or epigenetic factors. In addition, a point of major importance is that the pattern of progression that is observed in the model does not replicate that of some cases of LHON. Specifically, the 14484 LHON mutation has a better prognosis than the 3460 and 11778 mutations, with some patients showing visual improvement some time after the onset of symptoms. This clinical course is incompatible with the massive and irreversible cell loss induced by rotenone in the animal model. Similarly, the rotenone model does not resemble the time scale of LHON or other neurodegenerative diseases. In fact, the progression occurs in hours to days, whereas that of the LHON takes place in weeks to months. Although major aspects of the pathogenesis of neurodegeneration cannot be addressed in a reduce timescale as offered by the rotenone model, it provides an ideal context to conduct efficient drug development work.

\section{Conclusion}

Supporting and improving mitochondrial function has great potential as a therapeutic approach to neurodegeneration. A model of optic neuropathy induced by mitochondrial dysfunction has been developed to provide an ideal context for drug screening based on current data supporting the mitochondrial pathogenesis of neurodegenerative disorders of the eye and brain. The model addresses the environmental component in the pathogenesis of neurodegeneration and features biochemical, structural, and functional retinal deficits that resemble those of Leber's hereditary optic neuropathy. The model has been validated as a reliable tool for mechanistic experiments and provides an efficient standard for screening candidate neuroprotective interventions with a mitochondrial mechanism of action.

\section{References}

1. Whiting AS, Johnson LN. Papilledema: Clinical clues and differential diagnosis. Am Fam Physician. 1992;45(3):1125-1134.

2. Ramon y Cajal S. The structure and connections of neurons. In: Nobel Lectures, Physiology or Medicine 1901-1921. Vol 1. Amsterdam: Elsevier Publishing Company; 1967:220-253.
3. Hubel DH. Evolution of ideas on the primary visual cortex, 1955-1978: A biased historical account. In: Lindsten J, editor. Nobel Lectures, Physiology or Medicine 1981-1990. Vol 24-56. Singapore: World Scientific Publishing Co; 1993.

4. Howell N. Leber hereditary optic neuropathy: A model system for mitochondrial dysfunction and neurodegeneration. In: Beal MF, Howell N, Bodis-Wollner I, editors. Mitochondria and Free Radicals in Neurodegenerative Disorders. New York, NY: Wiley-Liss; 1997.

5. Dowding CH, Shenton CL, Salek SS. A review of the health-related quality of life and economic impact of Parkinson's disease. Drugs Aging. 2006;23(9):693-721.

6. Ernst RL, Hay JW. The US economic and social costs of Alzheimer's disease revisited. Am J Public Health. 1994;84(8):1261-1264.

7. Farlow M, Anand R, Messina J Jr, Hartman R, Veach J. A 52-week study of the efficacy of rivastigmine in patients with mild to moderately severe Alzheimer's disease. Eur Neurol. 2000;44(4):236-241.

8. Hung AY, Schwarzschild MA. Clinical trials for neuroprotection in Parkinson's disease: Overcoming angst and futility? Curr Opin Neurol. 2007;20(4):477-483.

9. Raskind MA, Peskind ER, Wessel T, Yuan W. Galantamine in AD: A 6-month randomized, placebo-controlled trial with a 6-month extension. The Galantamine USA-1 Study Group. Neurology. 2000;54(12):2261-2268.

10. Rogers SL, Farlow MR, Doody RS, Mohs R, Friedhoff LT. A 24-week, double-blind, placebo-controlled trial of donepezil in patients with Alzheimer's disease. Donepezil Study Group. Neurology. 1998;50(1):136-145.

11. Gonzalez-Lima F, Valla J, Jorandby L. Cytochrome oxidase inhibition in Alzheimer's disease. In: Gonzalez-Lima F, editor. Cytochrome Oxidase in Neuronal Metabolism and Alzheimer's Disease. New York, NY: Plenum Press; 1998.

12. Korlipara LV, Schapira AH. Parkinson's disease. In: Schapira AH, editor. International Review of Neurobiology. Vol 53. San Diego, CA: Academic Press; 2002.

13. Wallace DC, Lott MT, Brown MD. Mitochondrial defects in neurodegenerative diseases and aging. In: Beal MF, Howell N, Bodis-Wollner I, editors. Mitochondria and Free Radicals in Neurodegenerative Diseases. New York, NY: Wiley-Liss; 1997.

14. Henneberry RC. Excitotoxicity as a consequence of impairment of energy metabolism: The energy-linked excitotoxic hypothesis. In: Beal MF, Howell N, Bodis-Wollner I, editors. Mitochondria and free radicals in neurodegenerative diseases. New York, NY: Wiley-Liss; 1997.

15. Anandatheerthavarada HK, Devi L. Amyloid precursor protein and mitochondrial dysfunction in Alzheimer's disease. Neuroscientist. 2007;13(6):626-638.

16. Whitton PS. Inflammation as a causative factor in the aetiology of Parkinson's disease. Br J Pharmacol. 2007;150(8):963-976.

17. Beal MF. Aging, energy, and oxidative stress in neurodegenerative diseases. Ann Neurol. 1995;38(3):357-366.

18. Chalmers RM, Schapira AH. Clinical, biochemical and molecular genetic features of Leber's hereditary optic neuropathy. Biochim Biophys Acta. 1999;1410(2):147-158.

19. Wallace DC, Singh G, Lott MT, et al. Mitochondrial DNA mutation associated with Leber's hereditary optic neuropathy. Science. 1988;242(4884):1427-1430.

20. Erickson RP. Leber's optic atrophy, a possible example of maternal inheritance. Am J Hum Genet. 1972;24(3):348-349.

21. Yu-Wai-Man P, Griffiths PG, Hudson G, Chinnery PF. Inherited mitochondrial optic neuropathies. J Med Genet. 2009;46(3):145-158.

22. Majander A, Huoponen K, Savontaus ML, Nikoskelainen E, Wikstrom M. Electron transfer properties of $\mathrm{NADH}$ : Ubiquinone reductase in the ND1/3460 and the ND4/11778 mutations of the Leber hereditary optic neuroretinopathy (LHON). FEBS Lett. 1991;292(1-2):289-292.

23. Rizzo JF, 3rd. Adenosine triphosphate deficiency: A genre of optic neuropathy. Neurology. 1995;45(1):11-16.

24. Yen MY, Wang AG, Wei YH. Leber's hereditary optic neuropathy: A multifactorial disease. Prog Retin Eye Res. 2006;25(4):381-396.

25. Brown MD. The enigmatic relationship between mitochondrial dysfunction and Leber's hereditary optic neuropathy. J Neurol Sci. 1999;165(1):1-5. 
26. Genova ML, Ventura B, Giuliano G, et al. The site of production of superoxide radical in mitochondrial Complex I is not a bound ubisemiquinone but presumably iron-sulfur cluster N2. FEBS Lett. 2001;505(3):364-368.

27. Qi X, Sun L, Lewin AS, Hauswirth WW, Guy J. The mutant human ND4 subunit of complex I induces optic neuropathy in the mouse. Invest Ophthalmol Vis Sci. 2007;48(1):1-10.

28. Biousse V, Brown MD, Newman NJ, et al. De novo 14484 mitochondrial DNA mutation in monozygotic twins discordant for Leber's hereditary optic neuropathy. Neurology. 1997;49(4):1136-1138.

29. Johns DR, Smith KH, Miller NR, Sulewski ME, Bias WB. Identical twins who are discordant for Leber's hereditary optic neuropathy. Arch Ophthalmol. 1993;111(11):1491-1494.

30. Lam BL. Identical twins no longer discordant for Leber's hereditary optic neuropathy. Arch Ophthalmol. 1998;116(7):956-957.

31. Newman NJ, Lott MT, Wallace DC. The clinical characteristics of pedigrees of Leber's hereditary optic neuropathy with the 11778 mutation. Am J Ophthalmol. 1991;111(6):750-762.

32. Nikoskelainen EK, Savontaus ML, Wanne OP, Katila MJ, Nummelin KU. Leber's hereditary optic neuroretinopathy, a maternally inherited disease. A genealogic study in four pedigrees. Arch Ophthalmol. 1987;105(5):665-671.

33. Harding AE, Sweeney MG, Govan GG, Riordan-Eva P. Pedigree analysis in Leber hereditary optic neuropathy families with a pathogenic mtDNA mutation. Am J Hum Genet. 1995;57(1):77-86.

34. Johns DR, Smith KH, Miller NR. Leber's hereditary optic neuropathy. Clinical manifestations of the 3460 mutation. Arch Ophthalmol. 1992;110(11):1577-1581.

35. Kirkman MA, Yu-Wai-Man P, Korsten A, et al. Gene-environment interactions in Leber hereditary optic neuropathy. Brain. 2009;132 (Pt 9):2317-2326.

36. Smith PR, Cooper JM, Govan GG, Harding AE, Schapira AH. Smoking and mitochondrial function: A model for environmental toxins. $Q J$ Med. 1993;86(10):657-660.

37. Carelli V, Ross-Cisneros FN, Sadun AA. Optic nerve degeneration and mitochondrial dysfunction: Genetic and acquired optic neuropathies. Neurochem Int. 2002;40(6):573-584.

38. Carelli V, Ross-Cisneros FN, Sadun AA. Mitochondrial dysfunction as a cause of optic neuropathies. Prog Retin Eye Res. 2004;23(1):53-89.

39. Cursiefen C, Bergua A. Acute bilateral blindness caused by accidental methanol intoxication during fire "eating". Br J Ophthalmol. 2002;86(9):1064-1065.

40. Seme MT, Summerfelt P, Henry MM, Neitz J, Eells JT. Formateinduced inhibition of photoreceptor function in methanol intoxication. J Pharmacol Exp Ther. 1999;289(1):361-370.

41. Gorell JM, Johnson CC, Rybicki BA, Peterson EL, Richardson RJ. The risk of Parkinson's disease with exposure to pesticides, farming, well water, and rural living. Neurology. 1998;50(5):1346-1350.

42. Hertzman C, Wiens M, Snow B, Kelly S, Calne D. A case-control study of Parkinson's disease in a horticultural region of British Columbia. Mov Disord. 1994;9(1):69-75.

43. Semchuk KM, Love EJ, Lee RG. Parkinson's disease and exposure to agricultural work and pesticide chemicals. Neurology. 1992;42(7): 1328-1335.

44. Betarbet R, Sherer TB, MacKenzie G, Garcia-Osuna M, Panov AV, Greenamyre JT. Chronic systemic pesticide exposure reproduces features of Parkinson's disease. Nat Neurosci. 2000;3(12):1301-1306.

45. Lenaz G, Fato R, Genova ML, Bergamini C, Bianchi C, Biondi A. Mitochondrial Complex I: structural and functional aspects. Biochim Biophys Acta. 2006;1757(9-10):1406-1420.

46. Kudin AP, Bimpong-Buta NY, Vielhaber S, Elger CE, Kunz WS. Characterization of superoxide-producing sites in isolated brain mitochondria. J Biol Chem. 2004;279(6):4127-4135.

47. Hoegger MJ, Lieven CJ, Levin LA. Differential production of superoxide by neuronal mitochondria. BMC Neurosci. 2008;9:4.

48. Beretta S, Wood JP, Derham B, et al. Partial mitochondrial complex I inhibition induces oxidative damage and perturbs glutamate transport in primary retinal cultures. Relevance to Leber hereditary optic neuropathy (LHON). Neurobiol Dis. 2006;24(2):308-317.
49. Zhang X, Jones D, Gonzalez-Lima F. Mouse model of optic neuropathy caused by mitochondrial complex I dysfunction. Neurosci Lett. 2002;326(2):97-100.

50. Hayworth CR, Rojas JC, Gonzalez-Lima F. Transgenic mice expressing cyan fluorescent protein as a reporter strain to detect the effects of rotenone toxicity on retinal ganglion cells. J Toxicol Environ Health A. 2008;71(24):1582-1592.

51. Rojas JC, John JM, Lee J, Gonzalez-Lima F. Methylene blue provides behavioral and metabolic neuroprotection against optic neuropathy. Neurotox Res. 2009;15(3):260-273.

52. Rojas JC, Lee J, John JM, Gonzalez-Lima F. Neuroprotective effects of near-infrared light in an in vivo model of mitochondrial optic neuropathy. J Neurosci. 2008;28(50):13511-13521.

53. Rojas JC, Saavedra JA, Gonzalez-Lima F. Neuroprotective effects of memantine in a mouse model of retinal degeneration induced by rotenone. Brain Res. 2008;1215:208-217.

54. Zhang X, Jones D, Gonzalez-Lima F. Neurodegeneration produced by rotenone in the mouse retina: A potential model to investigate environmental pesticide contributions to neurodegenerative diseases. J Toxicol Environ Health A. 2006;69(18):1681-1697.

55. Zhang X, Rojas JC, Gonzalez-Lima F. Methylene blue prevents neurodegeneration caused by rotenone in the retina. Neurotox Res. 2006;9(1):47-57.

56. Battisti C, Formichi P, Cardaioli E, et al. Cell response to oxidative stress induced apoptosis in patients with Leber's hereditary optic neuropathy. J Neurol Neurosurg Psychiatry. 2004;75(12):1731-1736.

57. Wang JY, Gu YS, Wang J, Tong Y. Oxidative stress in Chinese patients with Leber's hereditary optic neuropathy. J Int Med Res. 2008;36(3):544-550.

58. Yen MY, Kao SH, Wang AG, Wei YH. Increased 8-hydroxy2'-deoxyguanosine in leukocyte DNA in Leber's hereditary optic neuropathy. Invest Ophthalmol Vis Sci. 2004;45(6):1688-1691.

59. Schuh RA, Matthews CC, Fishman PS. Interaction of mitochondrial respiratory inhibitors and excitotoxins potentiates cell death in hippocampal slice cultures. J Neurosci Res. 2008;86(15):3306-3313.

60. Hartwick AT, Hamilton CM, Baldridge WH. Glutamatergic calcium dynamics and deregulation of rat retinal ganglion cells. J Physiol. 2008;586(14):3425-3446

61. Khodorov BI, Storozhevykh TP, Surin AM, et al. The leading role of mitochondrial depolarization in the mechanism of glutamateinduced disruptions in Ca2+ homeostasis. Neurosci Behav Physiol. 2002;32(5):541-547.

62. Schuh RA, Kristian T, Gupta RK, Flaws JA, Fiskum G. Methoxychlor inhibits brain mitochondrial respiration and increases hydrogen peroxide production and CREB phosphorylation. Toxicol Sci. 2005;88(2): 495-504.

63. Kerrison JB, Howell N, Miller NR, Hirst L, Green WR. Leber hereditary optic neuropathy. Electron microscopy and molecular genetic analysis of a case. Ophthalmology. 1995;102(10):1509-1516.

64. Wong-Riley MT. Cytochrome oxidase: An endogenous metabolic marker for neuronal activity. Trends Neurosci. 1989;12(3):94-101.

65. Gonzalez-Lima F, Cada A. Quantitative histochemistry of cytochrome oxidase activity: Theory, methods, and regional brain vulnerability. In: Gonzalez-Lima F, editor. Cytochrome Oxidase in Neuronal Metabolism and Alzheimer's Disease. New York, NY: Plenum Press; 1998.

66. Grafstein B, Murray M, Ingoglia NA. Protein synthesis and axonal transport in retinal ganglion cells of mice lacking visual receptors. Brain Res. 1972;44(1):37-48.

67. Nikoskelainen E, Sogg RL, Rosenthal AR, Friberg TR, Dorfman LJ. The early phase in Leber hereditary optic atrophy. Arch Ophthalmol. 1977;95(6):969-978.

68. Kwittken J, Barest HD. The neuropathology of hereditary optic atrophy (Leber's disease); the first complete anatomic study. Am J Pathol. 1958;34(1):185-207.

69. Howell N, Mackey DA. Low-penetrance branches in matrilineal pedigrees with Leber hereditary optic neuropathy. Am J Hum Genet. 1998;63(4):1220-1224. 
70. Sadun AA, Salomao SR, Berezovsky A, et al. Subclinical carriers and conversions in Leber hereditary optic neuropathy: A prospective psychophysical study. Trans Am Ophthalmol Soc. 2006;104:51-61.

71. Sadun AA, Win PH, Ross-Cisneros FN, Walker SO, Carelli V. Leber's hereditary optic neuropathy differentially affects smaller axons in the optic nerve. Trans Am Ophthalmol Soc. 2000;98:223-232; discussion 232-225.

72. Ventura DF, Quiros P, Carelli V, et al. Chromatic and luminance contrast sensitivities in asymptomatic carriers from a large Brazilian pedigree of 11778 Leber hereditary optic neuropathy. Invest Ophthalmol Vis Sci. 2005;46(12):4809-4814.

73. Riordan-Eva P, Sanders MD, Govan GG, Sweeney MG, Da Costa J, Harding AE. The clinical features of Leber's hereditary optic neuropathy defined by the presence of a pathogenic mitochondrial DNA mutation. Brain. 1995;118(Pt 2):319-337.

74. Douglas RM, Neve A, Quittenbaum JP, Alam NM, Prusky GT. Perception of visual motion coherence by rats and mice. Vision Res. 2006;46(18):2842-2847.

75. Prusky GT, West PW, Douglas RM. Behavioral assessment of visual acuity in mice and rats. Vision Res. 2000;40(16):2201-2209.

76. Wong AA, Brown RE. Visual detection, pattern discrimination and visual acuity in 14 strains of mice. Genes Brain Behav. 2006;5(5):389-403.

77. Wakakura M, Yokoe J. Evidence for preserved direct pupillary light response in Leber's hereditary optic neuropathy. $\mathrm{Br} J$ Ophthalmol. 1995;79(5):442-446

78. Fleming SM, Zhu C, Fernagut PO, et al. Behavioral and immunohistochemical effects of chronic intravenous and subcutaneous infusions of varying doses of rotenone. Exp Neurol. 2004;187(2):418-429.

79. Rojas JC, Simola N, Kermath BA, Kane JR, Schallert T, GonzalezLima F. Striatal neuroprotection with methylene blue. Neuroscience. 2009;163(3):877-889.

80. Saravanan KS, Sindhu KM, Mohanakumar KP. Acute intranigral infusion of rotenone in rats causes progressive biochemical lesions in the striatum similar to Parkinson's disease. Brain Res. 2005;1049(2): 147-155.

81. Biss DP, Sumorok D, Burns SA, et al. In vivo fluorescent imaging of the mouse retina using adaptive optics. Opt Lett. 2007;32(6):659-661.

82. Maass A, von Leithner PL, Luong V, et al. Assessment of rat and mouse RGC apoptosis imaging in vivo with different scanning laser ophthalmoscopes. Curr Eye Res. 2007;32(10):851-861.

83. Qi X, Lewin AS, Hauswirth WW, Guy J. Optic neuropathy induced by reductions in mitochondrial superoxide dismutase. Invest Ophthalmol Vis Sci. 2003;44(3):1088-1096.

84. Qi X, Lewin AS, Hauswirth WW, Guy J. Suppression of complex I gene expression induces optic neuropathy. Ann Neurol. 2003;53(2):198-205.

85. Qi X, Lewin AS, Sun L, Hauswirth WW, Guy J. SOD2 gene transfer protects against optic neuropathy induced by deficiency of complex I. Ann Neurol. 2004;56(2):182-191.

86. Dhar SS, Wong-Riley MT. Coupling of energy metabolism and synaptic transmission at the transcriptional level: Role of nuclear respiratory factor 1 in regulating both cytochrome c oxidase and NMDA glutamate receptor subunit genes. J Neurosci. 2009;29(2):483-492.

87. Guzman-Barron ES, Hoffman LA. The catalytic effect of dyes on the oxygen consumption of living cells. J Gen Physiol. 1930;13:483-494.

88. Alberts B, Johnson A, Lewis J, Raff M, Roberts K, Walter P. Molecular Biology of the Cell. 4th ed. New York, NY: Garland Science; 2002.

89. Peter C, Hongwan D, Kupfer A, Lauterburg BH. Pharmacokinetics and organ distribution of intravenous and oral methylene blue. Eur J Clin Pharmacol. 2000;56(3):247-250.

Eye and Brain

\section{Publish your work in this journal}

Eye and Brain is an international, peer-reviewed, open access journal focusing on clinical and experimental research in the field of neuroophthalmology. All aspects of patient care are addressed within the journal as well as basic research. Papers covering original research, basic science, clinical and epidemiological studies, reviews and evaluations,

Submit your manuscript here: http://www.dovepress.com/eye-and-brain-journal
90. Walter-Sack I, Rengelshausen J, Oberwittler H, et al. High absolute bioavailability of methylene blue given as an aqueous oral formulation. Eur J Clin Pharmacol. 2009;65(2):179-189.

91. Buchholz K, Schirmer RH, Eubel JK, et al. Interactions of methylene blue with human disulfide reductases and their orthologues from Plasmodium falciparum. Antimicrob Agents Chemother. 2008;52(1):183-191.

92. Moosmann B, Skutella T, Beyer K, Behl C. Protective activity of aromatic amines and imines against oxidative nerve cell death. Biol Chem. 2001;382(11):1601-1612.

93. Salaris SC, Babbs CF, Voorhees WD, 3rd. Methylene blue as an inhibitor of superoxide generation by xanthine oxidase. A potential new drug for the attenuation of ischemia/reperfusion injury. Biochem Pharmacol. 1991;42(3):499-506.

94. Scott A, Hunter FE Jr. Support of thyroxine-induced swelling of liver mitochondria by generation of high energy intermediates at any one of three sites in electron transport. J Biol Chem. 1966;241(5):1060-1066.

95. Visarius TM, Stucki JW, Lauterburg BH. Stimulation of respiration by methylene blue in rat liver mitochondria. FEBS Lett. 1997;412(1): 157-160

96. Callaway NL, Riha PD, Bruchey AK, Munshi Z, Gonzalez-Lima F. Methylene blue improves brain oxidative metabolism and memory retention in rats. Pharmacol Biochem Behav. 2004;77(1):175-181.

97. Riha PD, Bruchey AK, Echevarria DJ, Gonzalez-Lima F. Memory facilitation by methylene blue: Dose-dependent effect on behavior and brain oxygen consumption. Eur J Pharmacol. 2005;511(2-3):151-158.

98. Wischik CM, Bentham P, Wischik DJ, Seng KM. Tau aggregation inhibitor (TAI) therapy with Rember ${ }^{\mathrm{TM}}$ arrests disease progression in mild and moderate Alzheimer's disease over 50 weeks. Alzheimer's and Dementia. 2008;4(4):T167.

99. Wainwright M, Crossley KB. Methylene blue - a therapeutic dye for all seasons? J Chemother. 2002;14(5):431-443.

100. Hamblin MR, Demidova TN. Mechanisms of low level light therapy. Proc of SPIE. 2006;6140:1-12.

101. Karu T. Laser biostimulation: A photobiological phenomenon. J Photochem Photobiol B. 1989;3(4):638-640.

102. Karu T. Mechanisms of low-power laser light action on cellular level. Proc of SPIE. 2000;4159:1-19.

103. Pastore D, Greco M, Passarella S. Specific helium-neon laser sensitivity of the purified cytochrome c oxidase. Int J Radiat Biol. 2000;76(6):863-870.

104. Eells JT, Wong-Riley MT, VerHoeve J, et al. Mitochondrial signal transduction in accelerated wound and retinal healing by near-infrared light therapy. Mitochondrion. 2004;4(5-6):559-567.

105. Liang HL, Whelan HT, Eells JT, et al. Photobiomodulation partially rescues visual cortical neurons from cyanide-induced apoptosis. Neuroscience. 2006;139(2):639-649.

106. Shefer G, Partridge TA, Heslop L, Gross JG, Oron U, Halevy O. Low-energy laser irradiation promotes the survival and cell cycle entry of skeletal muscle satellite cells. J Cell Sci. 2002;115(Pt 7): 1461-1469.

107. Eells JT, Henry MM, Lewandowski MF, Seme MT, Murray TG. Development and characterization of a rodent model of methanolinduced retinal and optic nerve toxicity. Neurotoxicology. 2000;21(3):321-330

108. Ellouze S, Augustin S, Bouaita A, et al. Optimized allotopic expression of the human mitochondrial ND4 prevents blindness in a rat model of mitochondrial dysfunction. Am J Hum Genet. 2008;83(3):373-387.

\section{Dovepress}

guidelines, expert opinion and commentary, case reports and extended reports are welcome. The manuscript management system is completely online and includes a very quick and fair peer-review system, which is all easy to use. Visit http://www.dovepress.com/testimonials.php to read real quotes from published authors. 